\title{
Motorcycle Red Box Evaluation at Signalized Intersections in Bogor: Traffic Flow, Occupancy Rate and Stop Line Violation
}

\author{
Agah Muhammad Mulyadi ${ }^{1, *}$ \\ ${ }^{I}$ Institute of Road Engineering, Ministry of Public Works of Indonesia \\ *Corresponding author: agah.muhammad@pusjatan.go.id
}

\begin{abstract}
The number of motorcycle's population until the end of 2016 was reach the peak around 98.2 million units and the sales was reach 5.93 million units. The accumulation of motorcycle disorderly movement at signalized intersection during waiting at the red light is a negative impact due to high motorcycle population. The red box is an alternative solution to increase signalized intersection performance. The aim of this paper is to evaluate the implementation of Red Box for motorcycle in relation to traffic flow, occupancy rate and traffic violations. The traffic flow analysis used the Indonesian road capacity manual while analysis of the occupancy rate and traffic violation method used the guidelines of Red Box monitoring. Analysis of the result showed that after implementation of the Red Box, traffic flow increased up to $15.64 \%$. The occupancy rate to the capacity increased around $22.70 \%$ to $38.40 \%$. Meanwhile, the Red Box occupancy by motorcycle was only around $33.33 \%$ to $68.33 \%$. The number of stop line violations decreased up to $89.88 \%$.
\end{abstract}

Keywords_-Traffic Survey, Assessment category, Bogor, Analysis, intersection approach, implementation.

\section{INTRODUCTION}

The number of vehicle in Indonesia rapidly increases, especially motorcycles. In almost two decades from 1996 to 2016 , the average of annual sales reaches 3.9 million units per year. The number of population until the end of 2016 was reach the peak around 98.2 million units and the sales was reach 5.93 million units.
The main attracted factors of the motorcycle used because of some reason, such as affordable purchase price, cost of daily operations are cheaper, easy and inexpensive to maintain, capable to reach remote areas, does not require a large parking space and tend to free of congestion. The population and sales of motorcycles in Indonesia is shown in Figure. 1.

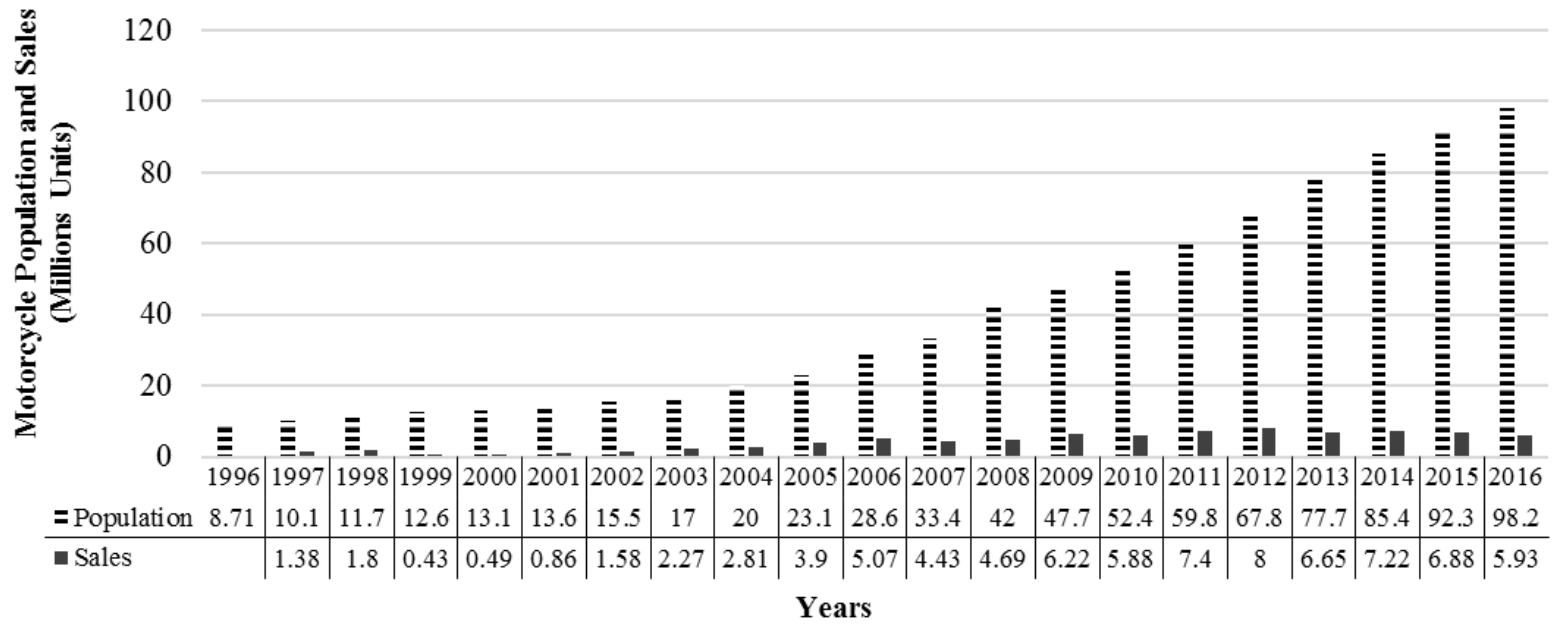

Figure. 1 Sales and Population of Motorcycle in Indonesia

The accumulation of motorcycle disorder movement at intersection approach while waiting at the red light is a negative impact due to high motorcycle population as shown in Figure 2. The motorcycle disorder movement had caused stop line violation, blocked the left turn and obstructed the pedestrian movement. Thus, the large number of motorcycles had affected the performance of signalized intersections by decreasing the capacity. 


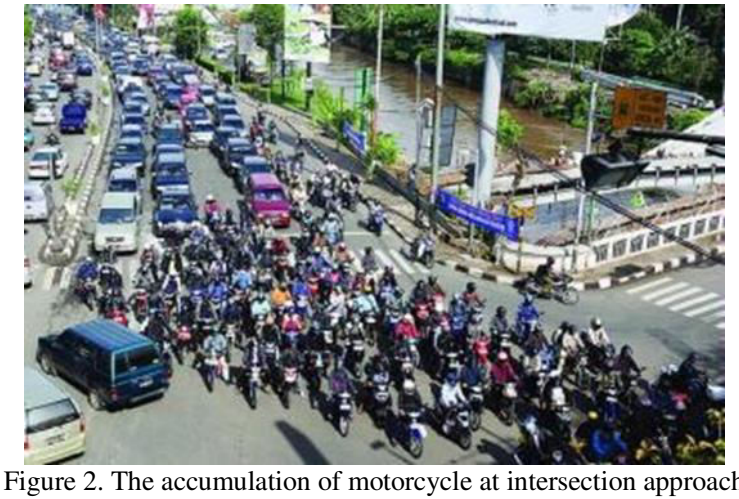

Bogor is the gateway of West Java Province, it is 60 $\mathrm{km}$ away from the capital city of Indonesia (Jakarta) and $120 \mathrm{~km}$ from the capital city of West Java (Bandung). A wide range of natural attractions, sport, culture, souvenirs, and variety of typical food and shopping malls as well as tourism and cultural activities can be found in Bogor. Consequently, Bogor becomes a tourist destination and a number of private vehicle increased, one of which was motorcycles. The traffic density in Bogor was dominated by motorcycles with high intensity both in the morning and afternoon.

In the morning, majority of people in Bogor work outside the city and people from outside the city come to the city for school or recreation trip and then continue back home in the afternoon. As a result, there are traffic problems at the signalized intersection. One of the solutions to solve these problems is providing the facility of Red Box for motorcycle. The trial implementation of the Red Box was at one signalized intersection at Pajajaran-Pangrango. The implementation of Red Box for motorcyles is shown in Figure 3.

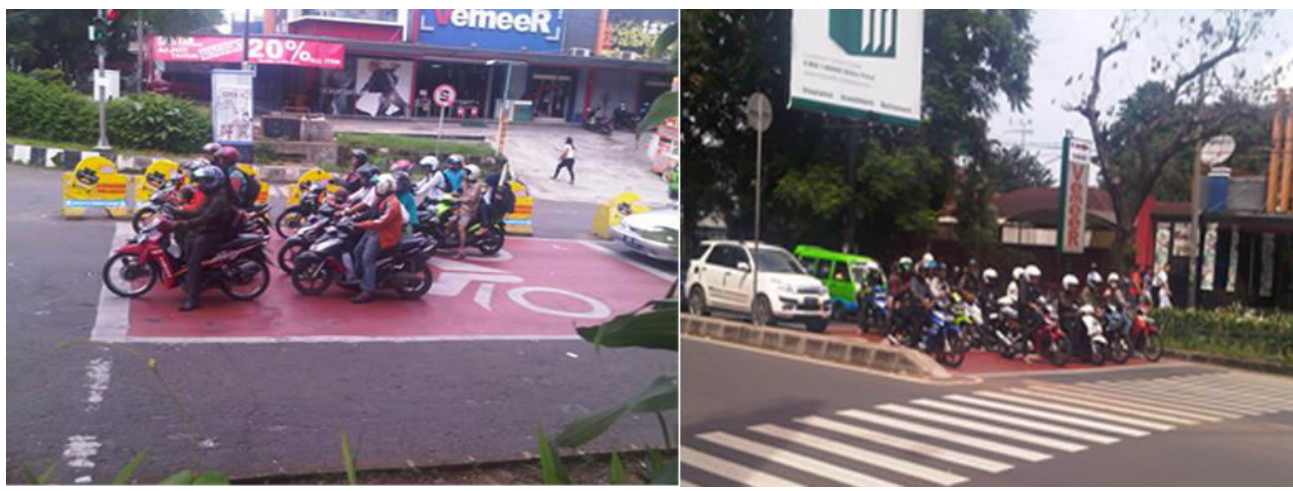

Figure 3. Implementation of Red Box for Motorcyle in Bogor

Implementation of Red Box for motorcycle at signalized intersections was developed from the concept of Advance Stop Lanes (ASL) for bicycles. ASL, also called advanced stop box or bike box, is road markings at signalized approach that allow certain types of vehicles to head start when the traffic signal changes from red to green. Advanced stop lines for bicycles were implemented widely in the United Kingdom, the Netherlands, Denmark, and other European countries. Therefore, this concept is tried to be implemented for motorcycles. The Red Box for motorcycle was developed to split the queue between motorcycles and other types of vehicles when waiting at red light. [1].

In general design, the first Red Box was designed by providing front stop line for motorcycle and back stop line for other types of vehicles. Both stop lines are separated by red area with solid marking. Red Box for motorcycle also continuous boundary road marking on the left and right side. There was motorcycle logo in the center of Red Box. That motorcycle logo was shown in the centre of red area to make motorcyclists easy to understand and aware what the meaning of Red Box is.

There are two types of Red Box for motorcycle, the box type and the $\mathrm{P}$ type. Box type is designed with box shape and it is applied if the proportion of motorcycle at each lane is relatively same.

$P$ type is designed with $P$ shape which is added by extension area at the left lane. This extension area is designed to accommodate the large proportion of motorcycle that moves on the left lane. $\quad \mathrm{P}$ type is only applied when the proportion of motorcycle on the left lane is greater than $60 \%$ and $70 \%$ for two lanes and three lanes of Red Box for motorcycle. On the contrary, if less than that value then the box type is applied. At this intersection, all Red Box was designed with box type and length $8 \mathrm{~m}$. Scooter matic and underbone have average length around $2 \mathrm{~m}$. Thus, the design Red Box with length of $8 \mathrm{~m}$ is able to accommodate four rows of motorcycles

Motorcycle in Indonesia is dominated by scooter matic $(51.6 \%)$ then followed by underbone $(40.35 \%)$ and sportbike $(8.05 \%)$. There are several types of motorcycles in indonesia, scooter matic is motorcycle that have scooter engine sizes range smaller than motorcycles, 50-85 cc (3.10-51.90 cu in), and have allenclosing bodywork that makes them cleaner and quieter than motorcycles, as well as having more built-in storage space. Automatic clutches and continuously variable transmissions (CVT) make them easier to learn on and to ride. Scooters usually have smaller wheels than motorcycles. Underbones are small-displacement motorcycle with a step-through frame. They are differentiated from scooters by their larger wheels and their use of footpegs instead of a floorboard. They often have a gear shifter with an automatic clutch. Sport bikes emphasize top speed, acceleration, braking, handling and grip on paved roads, typically at the expense of comfort and fuel economy in comparison to less specialized motorcycles. Sport bikes have comparatively high 
performance engines resting inside a lightweight frame (http://ridingsafely.com, 2016). Types of Red Box are shown in Figure 4 while terms of Red Box requirement are shown in Table 1.
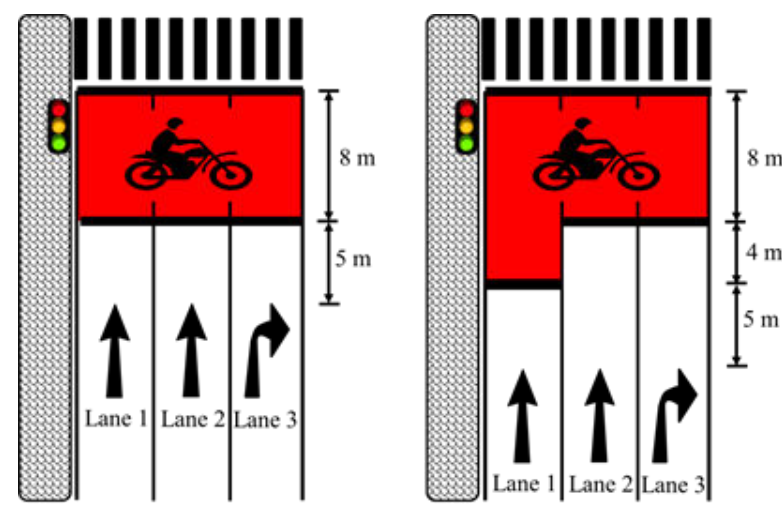

Figure 4. Design of Box Type and P Type

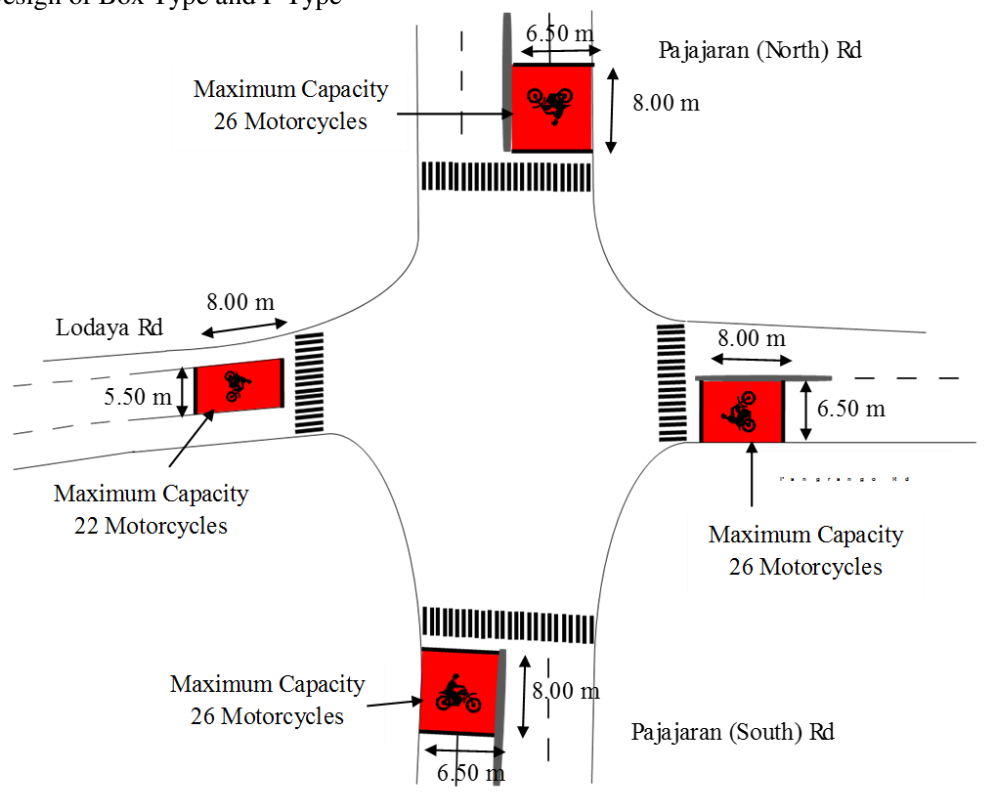

Figure 5. Design of Red Box at Pajajaran-Pangrango intersection

\section{METHOD}

Research methodology was divided into traffic survey method and analysis method which are explained as follows.

\section{A. Methodology of Traffic Survey}

Traffic survey was conducted one month before and two months after implementation of red motorcycle box. In addition, both data earlier were analyzed to be used as comparison data to determine the influence of Red Box implementation to the traffic flow, occupancy rate and stop line violation. Traffic survey was taken in three segmentations of time. The three segmentations were morning session (06.00am to 08.00am), day session (11.00 am to $01.00 \mathrm{pm})$ and afternoon session (04.00 pm to $06.00 \mathrm{pm}$ ). The survey was conducted as many as 20 traffic signal cycles/phases in each session in order to meet minimum requirement of 60 phases of traffic signals per day, it means 20 phases red in morning
Table 1 .

\begin{tabular}{cc}
\hline Parameter & Description \\
\hline Geometric & At least two lanes per direction which are not \\
& left turn directly \\
& $\begin{array}{c}\text { Width of each lanes approximately } 3.50 \mathrm{~m} \\
\text { At least } 30 \text { motorcycles on two lanes or } 45 \\
\text { Traffic Condition } \\
\text { motorcycles on three lanes during waiting at } \\
\text { the red light }\end{array}$ \\
\hline
\end{tabular}

At the Pajajaran-Pangrango signalized intersection, all Red Boxes were design by $8 \mathrm{~m}$ length. Design of Red Box is shown in Figure 5
Terms of Red Box Requirements session, 20 phases red in day session, 20 phases red in afternoon session. Survey time was conducted on weekdays.

Data collections technique was done by using video camera device. Video camera was designed to record the traffic volume at the signalized intersection. Video camera was installed at high place that could cover the whole traffic movement which was observed at the intersection. Video camera was installed at the pole with a height approximately 6 meter above road surface. The distance from Red Box to the pole was around 20 meter behind the Red Box. By using video record, the traffic volume was counted in the laboratory. Figure 6 showed video camera placement at the signalized intersection. 


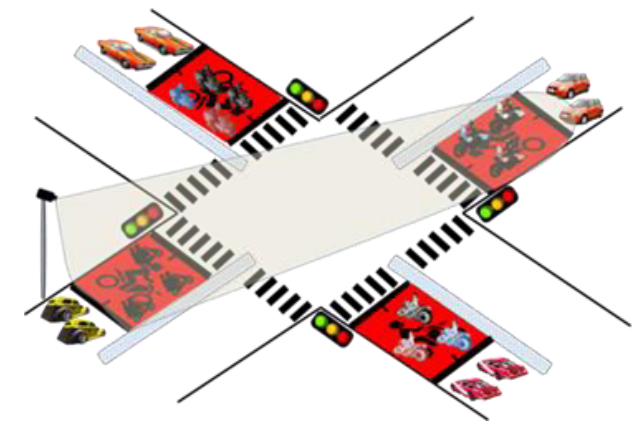

Figure 6. The camera placement at the Red Box location

\section{B. Methodology of Analysis}

Method of analysis was used to evaluate the performance of Red Box for motorcycles; traffic flow, occupancy rate and stop line violation.

\section{Methodology Analysis of Traffic Flow}

In order to find out that Red Box is able to make traffic flow more organized and smooth at signalized intersection, the traffic flow data were collected per 6 seconds to analyse the number of traffic flow at green light. The traffic volume was needed to measure the traffic flow, by converting the vehicles per hour to PCE per hour. Traffic volume is actual number of vehicles observed to pass a given point on the highway in a given time (The Minnesota Department of Transportation (DOT), 2016). In this research the traffic volume was counted per green light phase then the value was converted to per hour. Meanwhile Traffic Flow is the total number of vehicles passing a given point in a given time. Traffic flow is expressed as pce per hour. (https://transportist.org, 2016)

PCE (Passenger Car Equivalent) is a metric used in Transportation Engineering, to assess traffic-flow rate on a highway, a Passenger Car Equivalent is essentially the impact that a mode of transport has on traffic variables (such as headway, speed, density) compared to a single car (IATSS Research Vol.33 No.2, 2009). The PCE values determined for bus or truck was 1.30 , passenger car was 1.00, and motorcycle was 0.20 (Directorate General of Highways, 1997). Traffic flow related to the performance of signalized intersection.

It can be seen from Figure 7 that the traffic flow started from 0 second at the green light and it reached a peak after 12-18 seconds. After that the traffic flow decreased slightly and remained stable until the end of green light. At the beginning of traffic flow, lost time occured. Startup lost time happened when the traffic signal changed from red to green. Some amount of time elapsed between the signal changing from red to green and the first queue vehicle moving through the intersection. There is additional amount of time for the next vehicle to begin moving and passing through the intersection. The total time taken for all waiting drivers to react and accelerate was the start-up lost time. Clearance lost time is the time lost to stopping a line of vehicles at the end of a green light. Traffic flow was analysed by comparing data before and after implementation of the Red Box. The typical traffic flow diagram is shown in Figure 7 (Indonesia Road Capacity Manual, 1997).

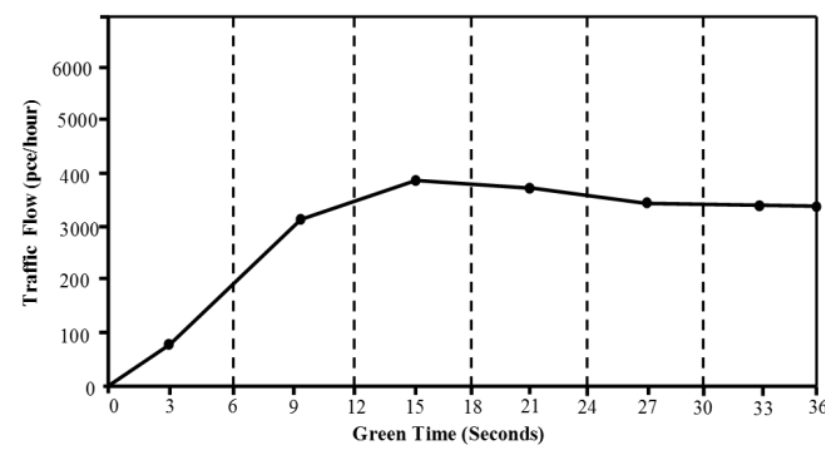

Figure 7. Typical traffic flow diagram

\section{Metodology Analysis of Occupancy Rate}

One of the indicators of success is the high occupancy rate of Red Box for motorcycle during the red light. Occupancy rate is the percentage of the number of motorcyles which occupied the red box during the red light to the maximum capacity/occupancy. Maximum occupancy is caunted by formula whereas Red Box area $\left(\mathrm{m}^{2}\right)$ is divided by the required area for one motorcyle while waiting at the Red Box $\left(\mathrm{m}^{2}\right)$. The area required for one motorcycle is $2.00 \mathrm{~m}^{2}$ ( $2 \mathrm{~m}$ length $\mathrm{x} 1 \mathrm{~m}$ width). Occupancy rate to the capacity is the percentage of the average number of motorcycles that occupied the Red Box to the maximum Red Box occupancy. Then occupancy rate by motorcycle only is the percentage of the number of red light phase that occupied by motorcycles only to the total number of red light. To calculate occupancy rate by motorcycles to the capacity is shown in equation 1 .

\section{Occupancy rate by motorcycles to the capacity =}

average number of motorcycles that occupied the Red Box maximum Red Box occupancy

Whereas:

maximum Red Box occupancy = area red box $(\mathrm{m} 2)$

required area for one motorcyle while waiting at the red box (m2)

Assessment of occupancy rate (IRE, 2012) was based on the guideline of monitoring and evaluation of the Red Box which is shown in Table 2 .

Table 2.

Assessment of occupancy rate by motorcycle to the capacity

$\begin{array}{cc}\text { Occupancy rate by Motorcycle to the Capacity } & \text { Assessment } \\ >80 \% & \text { Good } \\ 50 \%-80 \% & \text { Marginal } \\ <50 \% & \text { Poor }\end{array}$

The presence of non-motorcycles at the red box area during waiting at the red light, indicates less successful the implementation of the red box. This is due to lack of discipline, lack of rules awareness and inadequate design of the red box area. In addition, the assessment of occupancy rate by motorcycle only is shown in Table 3.

The presence of non-motorcycles at the Red Box area while waiting at the red light indicated marginal implementation of the Red Box. This is due to lack of discipline, lack of enforcement and inadequate design of the Red Box area. To calculate occupancy rate by 
motorcyles only is shown in equation 2 . In addition, the assessment of occupancy rate by motorcycle only (IRE, 2012) is shown in Table 3 while Illustration of only motorcycle or not only motorcycle occupied Red Box is shown in Figure 8.

Occupancy rate by motorcycles only $=$ $\frac{\text { the number of red light phase that occupied by motorcycles only }}{\text { the total number of red light }} \times 100 \%$

Table 3 .

Assessment of occupancy rate by motorcycle only

\begin{tabular}{cc}
\hline \multicolumn{2}{c}{ Assessment of occupancy rate by motorcycle only } \\
\hline Occupancy rate by motorcycle only & Assessment \\
\hline$>80 \%$ & Good \\
$50 \%-80 \%$ & Marginal \\
$<50 \%$ & Poor \\
\hline
\end{tabular}

Wrong $\rightarrow$ Not only motorcycle occupied the red box
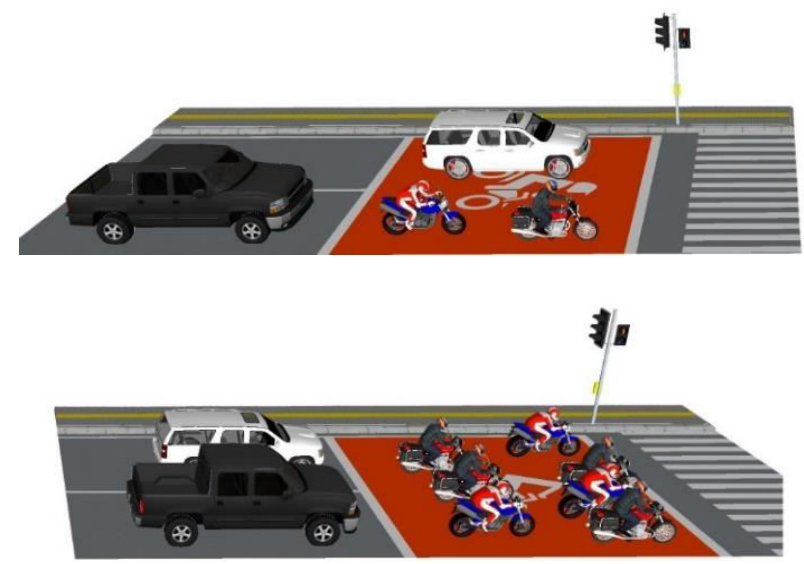

Correct $\rightarrow$ Only motorcyle occupied red box

Figure 8 . Illustration of only motorcycle or not only motorcycle occupied Red Box

3. Methodology of Analysis of Stop Line Violation

Red Box was intended to make the signalized intersection more organized, safe, and smooth. The stop line violation occured when the motorcycles were waiting at the red light and motorcyles stop in front of stop line. The stop line violation rate before and after implementation became an indicator of the Red Box success. If the stop line violation rate after the implementation of the Red Box does not decrease or remains stable, it is necessary to review the design of the Red Box or motorcyclist behaviors. The data were collected by surveyor by counting directly the number of motorcycles that violate at stop line on the site. The illustration of stop line violation is shown in Figure 9.

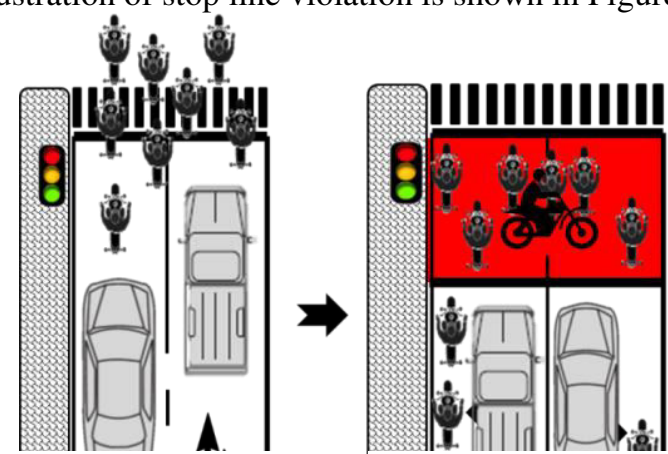

Before $\rightarrow$ Many motorcyles that violated of stop line

After $\rightarrow$ The Number of motorcycles that violated of stop line can be reduced

Figure 9. Illustration of Stop Line Violation (Before and After)

The success of the Red Box is shown by the decreasing number of stop line violation that could be measured by comparing the number of motorcycles that violated the stop line before and after Red Box implementation. To calculate stop line violation is shown in equation 3 while the assessment of stop line violation (IRE, 2012) is shown in Table 4.

Stop line violation $=$

Avg. motorcycles that violated the stop line (before)-

Avg.motorcycles that violated the stop line (after)

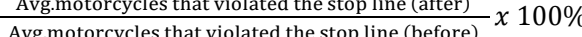

Whereas:

Avg. number of motorcycles that violated stop line $($ before or after $)=$

Number of motorcycles that violated the stop line when waiting during red light the total number of red light phase

Table 4

Assessment of Stop Line Violation

\begin{tabular}{cc}
\hline Stop line violation rate & Assessment \\
\hline Increase $\geq 0 \%$ & poor \\
Decrease $1 \%-35 \%$ & marginal \\
Decrease $36 \%-70 \%$ & good \\
Decrease $>70 \%$ & very good \\
\hline
\end{tabular}

\section{RESULT}

The data analysis was done by comparing before and after the Red Box implementation in terms of two parameters, i.e. traffic flow and stop line violation rate while the occupancy rate could only be measured after the Red Box implementation.

\section{A. Result of Traffic Flow Analysis}

According to the calculation of traffic volume data, it resulted a slight increasing number of traffic volume after the implementation of the Red Box from $0.84 \%$ to $14.45 \%$, except on Pajajaran Rd (North) that decreased by $3.15 \%$ in the morning. The changing of traffic volume is shown in Table 5. 
Table 5

The Changing of Traffic Volume

\begin{tabular}{|c|c|c|c|}
\hline \multirow[t]{2}{*}{ Intersection approach } & \multicolumn{3}{|c|}{$\begin{array}{l}\text { Change of Traffic Volume (Before and After) } \\
(\%)\end{array}$} \\
\hline & Morning & Day & Noon \\
\hline Lodaya & 6.04 & 0.94 & 7.56 \\
\hline Pajajaran (South) & 14.45 & 3.91 & 7.66 \\
\hline Pangrango & 11.11 & 1.66 & 9.00 \\
\hline Pajajaran (North) & -3.15 & 10.10 & 0.84 \\
\hline
\end{tabular}

By comparing before and after data, the highest increase of traffic volume was $14.45 \%$ which occured on Pajajaran (south) intersection approach in the morning. On the contrary, the highest decrease was $3.15 \%$ on Pajajaran (north) intersection approach in the morning.

The increase of average vehicle volume occurred in almost all intersection approach which was the influence of the Red Box implementation. By applying Red Box, the traffic flow became more organized so did the volume of vehicles that passed through the intersection which has increased. Head start motorcycle movement at the signalized intersection caused other types of vehicles are easily to move. Provides space for motorcyclists to stop in front of other types vehicles and can proceed through the intersection first when the light turns green caused many motorcycles move first, so the traffic flow is higher after implemented the red box. In addition, the changing of traffic flow at each intersection approach before and after implementation is shown in Table 6.
Table 6.

The Changing of Traffic Flow

\begin{tabular}{ccc}
\hline \multirow{2}{*}{ Intersection Approach } & Season & $\begin{array}{c}\text { Change of Traffic Flow } \\
\text { (Before and After) } \\
(\%)\end{array}$ \\
\hline \multirow{3}{*}{ Lodaya } & Morning & 6.22 \\
& Day & 0.89 \\
& Noon & 7.33 \\
Pajajaran (South) & Morning & 15.64 \\
& Day & 2.46 \\
& Noon & 7.08 \\
Pangrango & Morning & 12.17 \\
& Day & 0.51 \\
& Noon & 9.67 \\
Pajajaran (North) & Morning & -3.43 \\
& Day & 10.85 \\
& Noon & 0.19 \\
\hline
\end{tabular}

The highest increase of traffic flow was $15.64 \%$ at Pajajaran (south) intersection approach in the morning. Meanwhile, the highest decrease of traffic flow was at Pajajaran (north) intersection approach by $3.43 \%$ in the morning. In general, the increasing number of traffic flow occurred in Pajajaran-Pangrango intersection, so the Red Box made the intersection become more smooth.

\section{B. Result of Occupancy Rate and Stop Line Violation Analysis}

Red Box in Bogor has four intersection approaches. Firstly, Lodaya road that has an area of Red Box around $44 \mathrm{~m}^{2}$ and it has the capacity of 22 motorcycles. According to the data survey as shown in Figure 10, the average number of motorcycles which waited during the red light was approximately 5 motorcycles per phase. It means the Red Box has only occupied approximately $22.70 \%$ of capacity. There were 60 phases of red light that were surveyed per one intersection approach. The number of motorcycles that broke stop line after red box implementation was approximately 3.07 (decrease $16.19 \%)$.

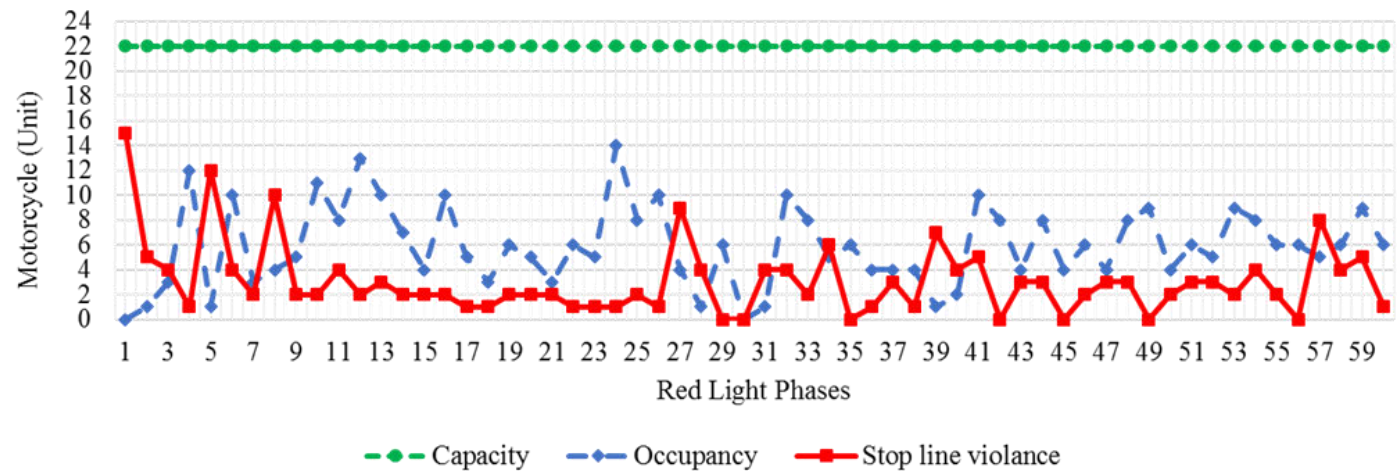

Figure 10. Occupancy and stop line violation at lodaya intersection approach

Table 7.

Assessment result at lodaya intersection approach

\begin{tabular}{|c|c|c|c|c|c|}
\hline No & Data Analysis Parameter & Result $(\%)$ & Assessment & \multicolumn{2}{|c|}{ Remarks } \\
\hline 1 & Occupancy rate to capacity & 22.70 & Poor & & \\
\hline 2 & Occupancy rate by motorcycle only & 33.33 & Poor & & \\
\hline 3 & Stop line violation & -16.19 & Marginal & $\begin{array}{c}\text { Before } \\
3.66\end{array}$ & $\begin{array}{c}\text { After } \\
3.07\end{array}$ \\
\hline
\end{tabular}

Secondly, the Pajajaran (south) intersection approach that has a size around $52 \mathrm{~m}^{2}$ and the capacity of around 26 motorcycles. At this intersection approach, the average number of Red Box occupancy was as many as 9 units of motorcycles per red light. Thus, it was only $34.60 \%$ of the capacity. The number of motorcycles that 
broke the stop line line after red box implementation is 0.27 (decrese $79.14 \%$ ). The occupancy and stop line violation at Pajajaran (south) intersection approach is shown in Figure 11.

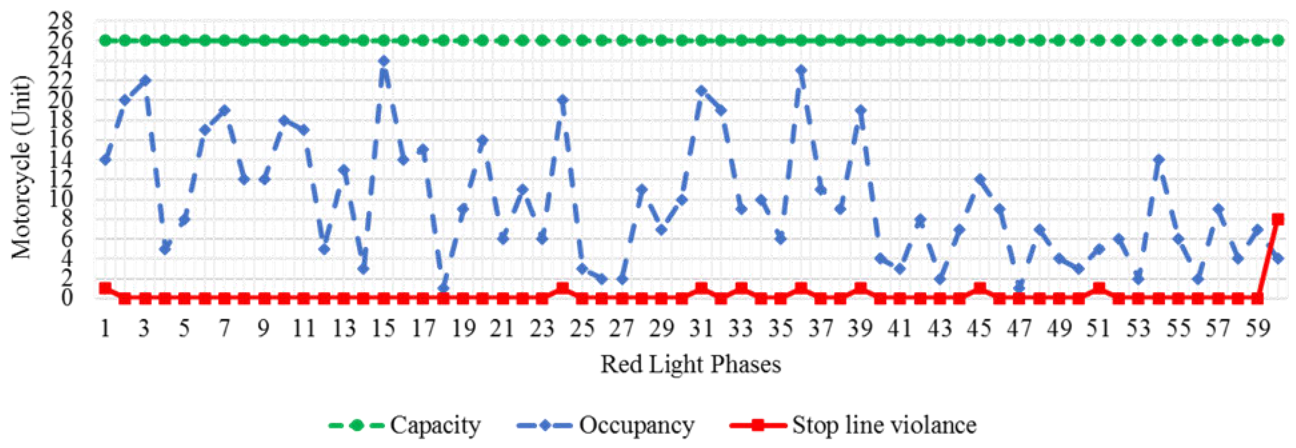

Figure 11. Occupancy and Stop Line Violation at Pangrango Intersection Approach

Table 8.

Assessment result at pajajaran (south) intersection approach

\begin{tabular}{cllllc}
\hline No & Data Analysis Parameter & Result $(\%)$ & Assessment & \multicolumn{2}{c}{ Remarks } \\
\hline 1 & Occupancy rate to capacity & 34.60 & Poor & & \\
2 & Occupancy rate by motorcycle only & 68.33 & Marginal & & \\
3 & Stop line violation & -79.14 & very good & Before & After \\
& & & & 1.29 & 0.27 \\
\hline
\end{tabular}

Thirdly, Pangranggo road that has the Red Box area around $52 \mathrm{~m}^{2}$ and the capacity reached 26 motorcycles. The average occupancy of the Red Box was only 10 motorcycle units or approximately $38.40 \%$ of capacity per red light phase. Furthermore, the number of motorcycles that broke the stop line after red box implementation is 0.77 (decrese 89.88\%). The occupancy and stop line violation can be seen in Figure. 12.

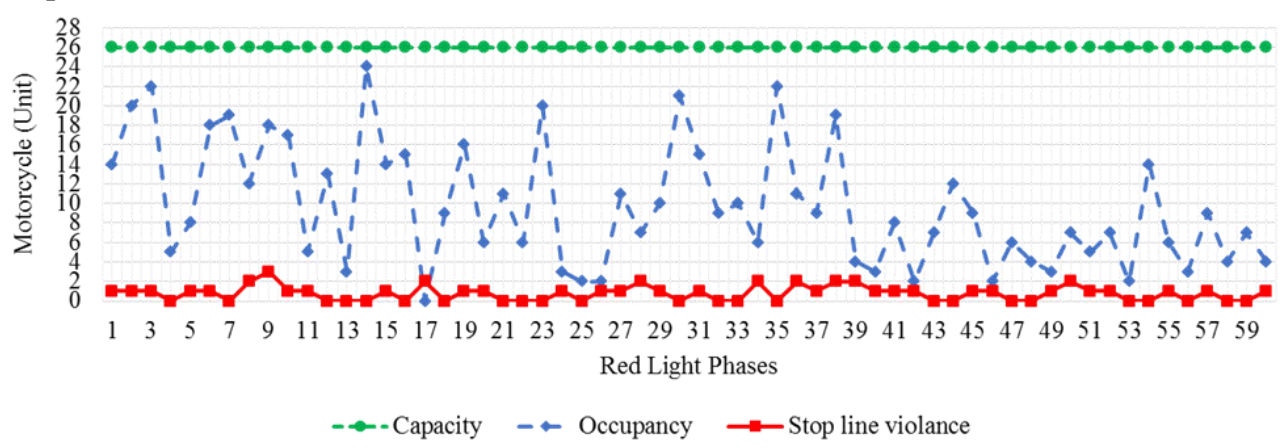

Figure 12. Occupancy and Stop Line Violation at Pajajaran Intersection Approach

Table 9.

Assessment result at pangrango intersection approach

\begin{tabular}{cllllc}
\hline No & Data Analysis Parameter & Result $(\%)$ & Assessment & \multicolumn{2}{c}{ Remarks } \\
\hline 1 & Occupancy rate to capacity & 38.40 & Poor & & \\
2 & Occupancy rate by motorcycle only & 43.33 & Poor & Before & After \\
3 & Stop line violation & -89.88 & very good & 7.60 & 0.77 \\
\hline
\end{tabular}

Fourthly, Pajajaran road (north) that has a size area of the Red Box around $52 \mathrm{~m}^{2}$ and the capacity reached 26 motorcycles per red light. The occupancy of the Red Box by motorcycle at this intersection approach had an average of 10 motorcycle units or approximately $38.40 \%$ of the capacity. In addition, the number of motorcycles that broke the stop line after red box implementation is 0.23 (decrese $72.56 \%$ ). The occupancy and stop line violation can be seen in Figure 13. 


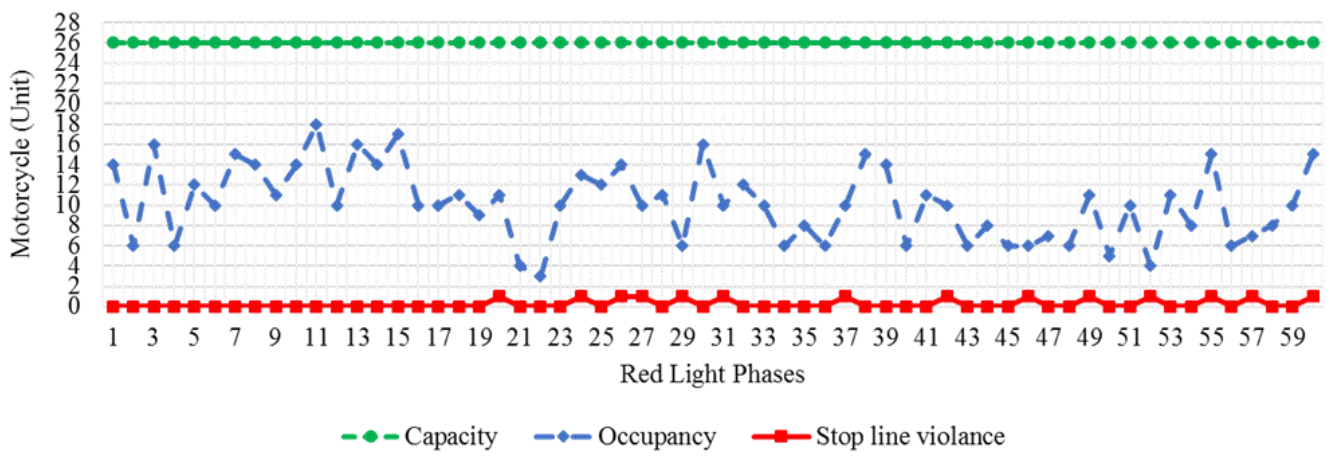

Figure 13. Occupancy and stop line violation at pajajaran (north) intersection approach

Table 10.

Assessment result at pajajaran (north) intersection approach

\begin{tabular}{llllrc}
\hline No & Data Analysis Parameter & Result $(\%)$ & Assessment & Remarks & \\
\hline 1 & Occupancy rate to capacity & 38.40 & Poor & & \\
2 & Occupancy rate by motorcycle only & 65.00 & Marginal & & \\
3 & Stop line violation & -72.56 & Good & Before & After \\
& & & & 0.84 & 0.23 \\
\hline
\end{tabular}

\section{RESULTS AND DISCUSSION}

Evaluation of the red motorcycle box showed a noticeable result. The conclusions of Red Box implementation in Bogor are as follow:

1. The highest increase of traffic flow occurred at intersections approach of Pajajaran Rd (south) in the morning and the most significant decrease occurred at the intersection approach of Pajajaran Rd (north) in the morning. Head start motorcycle movement at the signalized intersection caused other types of vehicles are easily to move. Provides space for motorcyclists to stop in front of other types vehicles and can proceed through the intersection first when the light turns green caused many motorcycles move first, so the traffic flow is higher after implemented the red box. In general, an increase in traffic flow occurred at the intersection. Thus, the Red Box was effective to make the intersection more smooth.

2. According to the motorcycle occupancy rates at the Red Box and the results of the Assessment, The analysis showed that the assessment results were poor. It was due to the low volume of motorcycles that passed the intersection and was also caused by blocked motorcycle access by four-wheel vehicles or more. Consequently motorcycles could not enter the Red Box area.

3. Based on the analysis of the Red Box occupied only by motorcycle, there were two intersection approach assessed in the category of marginal ie Pajaran road (north) and Pajajaran road (south). Meanwhile, the other two intersection approaches, Lodaya road and Pangrango road were marginal which was caused by many mini buses as a local public transport that stopped to board and alight passengers at the Red Box area. Meanwhile on Pangrango road it was caused by insufficient visibility for non motorcycle driver to anticipate the Red Box area in the front because of the curve road geometric just before entering the Red Box area.
4. The stop line violation at Pangrango and Pajajaran (south) intersection approach had Assessment category which was very good while on Pajajaran (north) intersection approach the Assessment category was good. In addition, on Lodaya road the Assessment category was marginal which was caused by uphill road surface, therefore the motorcycles tended to move forward to the flat road surface which was in front of the stop line.

5. Implementation of the Red Box is a something new for motorcyclists and other drivers, so the continuous education approach will be needed to make the implementation of the Red Box more successful in the future.

The conclusions of red box implementation in Bogor city as follow:

1. The highest increased traffic flow occurred at intersections approach of Lodaya in the afternoon and the highest decreased occurrs at the intersection approach of Pajajaran road (south) in the afternoon. In general, an increase in traffic flow occurred at the intersection. Thus, the red box is quite effective to make the intersection more smoothly

2. According to the motorcycle occupancy rates at the red box and the results of the assessment. The analysis shown that the Assessment results are less successful. This is due to the low volume of motorcycles that passing on the intersection and also caused by blocking of motorcycle access by fourwheel vehicles or more. Consequently motorcycles could not entering the red box area.

3. Based on the analysis of the red box occupied only by motorcycle, there are two intersections approach assess in the category of quite successful ie Pajaran road (north) and Pajajaran road (south). Meanwhile, the other two intersections approach, Lodaya road and Pangrango road are less successful category caused by many mini bus as a local public transport are stops to board and alight passenger at the red box area. Meanwhile on Pangrango road caused by 
insufficient visibility for non motorcycle driver to anticipate the red box area in the front because of the curve road geometric just before entering the red box area.

4. The stop line violation at the Pangrango and Pajajaran (south) intersection approach has Assessment category are very successful while on the Pajajaran (north) intersection approach the Assessment category is successful. In addition, on Lodaya road the Assessment category is quite successful which caused by uphill road surface, therefore the motorcycle tends to move forward to the flat road surface which is in the front of the stop line.

\section{REFERENCES}

[1] M. Idris, "The effect of advanced stop lines for motorcycles on traffic conflict at one signalized intersection in Bandung," Institut Teknologi Bandung, 2007.

[2] Board of Statistic Centre, 2014, Vehicle Development Based on Types of Vehicle. Jakarta.

[3] Institute of Road Engineering (IRE), 2012. Guideline of red box monitoring and evaluation. Bandung.

[4] Ministry of Public Works, 1997. Indonesia Road Capacity Manual (MKJI). Jakarta

[5] Puslitbang Jalan dan Jembatan, Kementerian Pekerjaan Umum, 2010, Kajian dan pengawasan uji skala penuh lajur khusus sepeda motor di persimpangan, Bandung.

[6] Puslitbang Jalan dan Jembatan, Kementerian Pekerjaan Umum, 2010, Penyusunan DED lajur sepeda motor pada persimpangan dan kajian lajur sepeda motor pada ruas jalan arteri, Puslitbang Jalan dan Jembatan, Kementerian Pekerjaan Umum, Bandung, Bandung.

[7] Ministry of Public Works and Housing, 2015. Pedoman perancangan Ruang Henti Khusus (RHK) sepeda motor pada simpang bersinyal di perkotaan. Bandung.

[8] Puslitbang Jalan dan Jembatan, Kementerian Pekerjaan Umum, 2012. Advis Teknis Ruang Henti Khusus (RHK) Sepeda Motor di Bogor. Jakarta 